Cornell University Law School Scholarship@Cornell Law: A Digital Repository

\title{
Significant Association Between Punitive and Compensatory Damages in Blockbuster Cases: A Methodological Primer
}

Theodore Eisenberg

Cornell Law School, ted-eisenberg@lawschool.cornell.edu

Martin T. Wells

Cornell University, mtw1@cornell.edu

Follow this and additional works at: http://scholarship.law.cornell.edu/facpub

Part of the Applied Statistics Commons, Litigation Commons, and the Remedies Commons

\section{Recommended Citation}

Eisenberg, Theodore and Wells, Martin T., "Significant Association Between Punitive and Compensatory Damages in Blockbuster Cases: A Methodological Primer" (2006). Cornell Law Faculty Publications. Paper 361.

http://scholarship.law.cornell.edu/facpub/361 


\title{
The Significant Association Between Punitive and Compensatory Damages in Blockbuster Cases: A Methodological Primer
}

\author{
Theodore Eisenberg and Martin T. Wells*
}

\begin{abstract}
This article assesses the relation between punitive and compensatory damages in a data set, gathered by Hersch and Viscusi (H-V), consisting of all known punitive damages awards in excess of $\$ 100$ million from 1985 through 2003. It shows that a strong, statistically significant relation exists between punitive and compensatory awards, a relation that replicates similar findings in nearly all other analyses of punitive and compensatory damages. H-V's claim that no significant relation exists between punitive and compensatory awards in these data appears to be an artifact of questionable regression methodology.
\end{abstract}

This article focuses on methodological issues in assessing the pattern of large punitive awards and other skewed data sets. Large punitive awards are one of the least explored empirical frontiers for punitive damages researchers. Multiple studies involving different, comprehensive data sets have yielded consistent results for several issues. Punitive awards were claimed to be frequent and increasing dramatically in number. Yet virtually all empirical research finds them to be only rarely awarded, ${ }^{1}$ to be most frequently

\footnotetext{
*Eisenberg is Henry Allen Mark Professor of Law, Cornell Law School, Myron Taylor Hall, Ithaca, NY 14853; email: theodore-eisenberg@postoffice.law.cornell.edu. Wells is Professor of Statistics, Department of Social Statistics, Cornell University, Professor of Clinical Epidemiology, Cornell University Weill Medical College, and Elected Member of the Law Faculty, Cornell University.
}

${ }^{1}$ For example, Thomas A. Eaton, David B. Mustard \& Susette M. Talarico, The Effects of Seeking Punitive Damages on the Processing of Tort Claims, 34 J. Legal Stud. 343 (2005); Thomas A. Eaton, Susette M. Talarico \& Richard E. Dunn, Another Brick in the Wall: An Empirical Look 
awarded in cases where intentional misbehavior likely occurred, ${ }^{2}$ and not to be increasing over time. ${ }^{3}$ Another punitive damages theme had juries pulling numbers out of the air in picking punitive awards. ${ }^{4}$ Yet no evidence supporting such systematic occurrences in real cases has been presented. To the contrary, the mass of cases reveal strong statistically significant relationships between compensatory and punitive awards. ${ }^{5}$ Extreme anecdotes about a punitive damages system out of control are regularly offered; but few withstand scrutiny by professional researchers. The poster-child case for punitive damages reform-the McDonald's coffee-spill case-turns out hardly to be the stuff on which to base massive tort reform. ${ }^{6}$

\begin{abstract}
at Georgia Tort Litigation in the 1990s, 34 Ga. L. Rev. 1049, 1094 (2000); Theodore Eisenberg, Neil LaFountain, Brain Ostrom, David Rottman \& Martin T. Wells, Juries, Judges, and Punitive Damages: An Empirical Study, 87 Cornell L. Rev. 743, 745 (2002) [hereinafter "Juries and Judges"]; Theodore Eisenberg, John Goerdt, Brian Ostrom, David Rottman \& Martin T. Wells, The Predictability of Punitive Damages, 26 J. Legal Stud. 623, 633-37 (1997) (summarizing studies) [hereinafter "Predictability"]; Neil Vidmar \& Mary R. Rose, Punitive Damages by Juries in Florida: In Terrorem and in Reality, 38 Harv. J. Legis. 487, 487 (2001).
\end{abstract}

${ }^{2}$ Eisenberg et al., Predictability, supra note 1; Erik Moller, Trends in Civil Jury Verdicts Since 1985 (1996).

${ }^{3}$ Theodore Eisenberg, Paula L. Hannaford-Agor, Michael Heise, Neil LaFountain, G. Thomas Munsterman, Brian Ostrom \& Martin T. Wells, Juries, Judges, and Punitive Damages: Empirical Analyses Using the Civil Justice Survey of State Courts 1992, 1996, and 2001 Data, 3 J. Empirical Legal Stud. (2006) (forthcoming).

4"Legislation is needed because punitive damages are wildly unpredictable, so arbitrary as to be unfair and are awarded without any guidance to juries, which simply pick numbers out of the air.” Editorial, Trial Lawyers' Triumph, Wash. Post, Mar. 19, 1996, 1996 WL 3069750.

${ }^{5}$ For example, Eisenberg et al., Juries and Judges, supra note 1, at 773-74; Eisenberg et al., Predictability, supra note 1; Margo Schlanger, Inmate Litigation, 116 Harv. L. Rev. 1555, 1605-05 \& n.136 (2003); Catherine M. Sharkey, Dissecting Damages: An Empirical Exploration of Sexual Harassment Awards, 3 J. Empirical Legal Stud. 1-43 (2006).

${ }^{6}$ Liebeck v. McDonald's Rests., P.T.S., Inc., No. CV 93-02419, 1995 WL 360309 (D.N.M. Aug. 18, 1994). The jury awarded $\$ 160,000$ in compensatory damages for severe burns suffered by the plaintiff and $\$ 2,700,000$ in punitive damages. The trial judge reduced the punitive award to $\$ 480,000$. The case was ultimately settled, presumably for a lesser amount still. For discussion of this case, see, e.g., William Haltom \& Michael McCann, Distorting the Law: Politics, Media, and the Litigation Crisis 183-226 (2004); Theodore Eisenberg, Use It or Pretenders Will Abuse It: The Importance of Archival Legal Information, 74 UMKC L. Rev. (forthcoming); Samuel R. Gross \& Kent D. Syverud, Don't Try: Civil Jury Verdicts in a System Geared to Settlement, 44 UCLA L. Rev. 1, 4 (1996); Neil Vidmar, Felicia Gross \& Mary Rose, Jury Awards for Medical Malpractice and Post-Verdict Adjustments of the Awards, 48 DePaul L. Rev. 265, 266 (1998); 
With horror stories about punitive damages' high frequency and lack of relation to compensatory awards discredited, one of the last empirical frontiers is large punitive awards. It no longer is the mass of punitive awards that is said to be so troublesome. Rather, it is the relative handful of extreme awards. A recently available data set enables systematic exploration of large punitive awards. Joni Hersch and W. Kip Viscusi (H-V) gathered data on the largest punitive damages awards, those in excess of $\$ 100$ million. ${ }^{7}$ Their analysis claims that these "blockbuster" punitive damages awards bear no relation to compensatory awards. We explore the pattern of large awards using the H-V data. Traditional statistical methods, applied somewhat more rigorously than $\mathrm{H}-\mathrm{V}$ apply them, reveal a reasonably strong association between punitive and compensatory damages. Analysis of the H-V data set also serves as a reminder that regression models are best employed after inspecting the data, and best relied on when assumptions concerning the models have been checked. The ease of modern computing and the impressive power of regression methodology may result in an understandable tendency to regress without sufficient attention to important details. This risks yielding both spurious results and having nontechnical scholars naively rely on reported results. ${ }^{8}$

\section{The Hersch-Viscusi Data}

$\mathrm{H}-\mathrm{V}$ analyze the relation between punitive and compensatory awards in 63 tried cases decided from January 1985 to June 2003. The cases were collected using "a detailed search to identify all cases for which there were punitive damages of at least $\$ 100$ million." $"$ During the same time period, H-V found three bench trials resulting in a punitive damages award in excess of $\$ 100$ million. Contrary to findings in several other data sets, H-V report no mean-

Andrea Gerlin, A Matter of Degree: How a Jury Decided that a Coffee Spill Is Worth $\$ 2.9$ Million, Wall St. J., Sept. 1, 1994, at A1.

${ }^{7}$ Joni Hersch \& W. Kip Viscusi, Punitive Damages: How Judges and Juries Perform, 33 J. Legal Stud. 1 (2004).

${ }^{8} \mathrm{~A}$ recent instance of too hasty reliance on regression results may be regression-based assertions that the death penalty deters homicides. See Richard Berk, New Claims about Executions and General Deterrence: Déjà Vu All Over Again?, 2 J. Empirical Legal Stud. 303 (2005).

${ }^{9}$ Hersch \& Viscusi, supra note 7 , at 4-5. 
Table 1: Mean and Median Compensatory Punitive Award (in Thousands) Jury Trial Cases with Punitive Damages of at Least \$100 Million, 1985-2003

\begin{tabular}{lrrrrr}
\hline & \multicolumn{1}{c}{ Mean } & Median & Minimum & Maхimum & N \\
\hline Compensatory award & 217,317 & 23,318 & 170 & $7,530,000$ & 60 \\
Punitive award & $3,506,958$ & 200,000 & 100,000 & $144,871,400$ & 60 \\
\hline
\end{tabular}

NotE: Data consist of 60 jury-tried cases with punitive awards of $\$ 100$ million or more, from 1985-2003, as reported in Hersch and Viscusi, Journal of Legal Studies 2004.

ingful relation between punitive awards and compensatory awards in the same case. "Analysis of these very large awards indicates that they bear no statistical relation to the compensatory awards." ${ }^{10}$ More rigorous analyses than H-V's initial pass at the data suggest that this conclusion is questionable. Traditional regression tools suggest that the relation between punitive and compensatory awards in large cases is stronger than that reported by $\mathrm{H}-\mathrm{V}$.

\section{The Relation Between Punitive AND Compensatory Awards}

Understanding why H-V understate the relation between punitive and compensatory awards requires reviewing basic principles of statistical analysis of the relation between two continuous variables. Summary statistics of their punitive and compensatory award jury trial data are in Table 1 . The table indicates that the data are skewed in the sense that the means of both the compensatory and punitive awards are much greater than the medians. The median punitive award is $\$ 200$ million, whereas the mean punitive award exceeds $\$ 3$ billion. The median compensatory award is about $\$ 23$ million and the median compensatory award is about $\$ 200$ million. The medians and means are strikingly high but recall that this is a data set selected using punitive awards of $\$ 100$ million or more as the selection criteria, so strikingly large summary statistics should not be surprising.

\section{A. The Importance of Graphing the Data}

These summary statistics raise the likelihood that the data are in some sense extreme. It is helpful, as always, to graph the data to explore the relation between punitive and compensatory awards. A scatterplot of the data is often

\footnotetext{
${ }^{10}$ Id. at 2.
} 
Figure 1: Punitive versus compensatory damages: punitive awards of at least $\$ 100,000,000,1985-2003$.

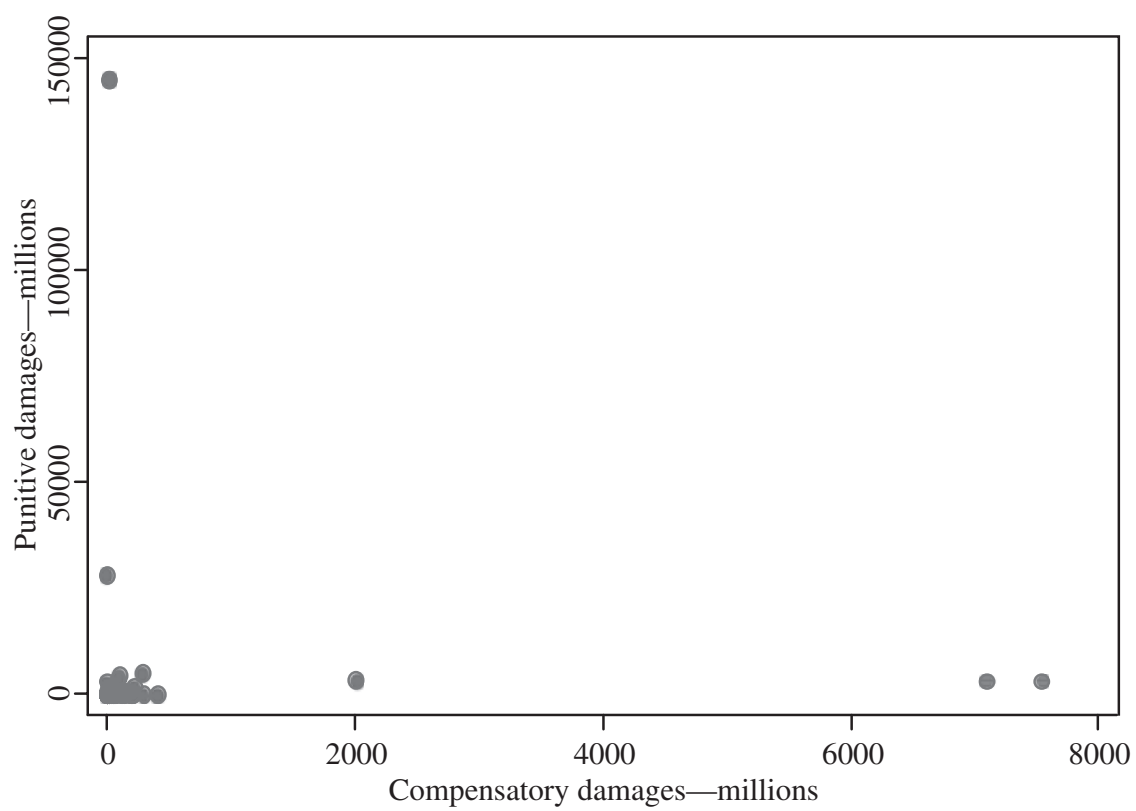

SOURCE: Hersch-Viscusi, Journal of Legal Studies 2004.

the first step in exploring the relation between two continuous variables. ${ }^{11}$ Figure 1 is a scatterplot of the compensatory and punitive data. To help put the graphical pattern in Figure 1 in perspective, we report in Figure 2 a second data set, often used in statistical discussions, consisting of the relation between mammalian body weight and brain weight.

An introductory regression book's discussion of the mammal data in Figure 2 is instructive.

The initial attempt to graph brain weight (in grams) versus body weight (in kilograms) ... indicates immediately that some sort of transformation is required. Most of the points in the plot are jammed into the lower left-hand

\footnotetext{
${ }^{11}$ For example, Sanford Weisberg, Applied Linear Regression 1 (3d ed. 2005) ("In regression problems with one predictor and one response, the scatterplot of the response versus the predictor is the starting point for regression analysis."); Lawrence E. Hamilton, Regression with Graphics 34 (1992) (scatterplots are basic tools in regression).
} 
Figure 2: Brain weight versus body weight, mammals.

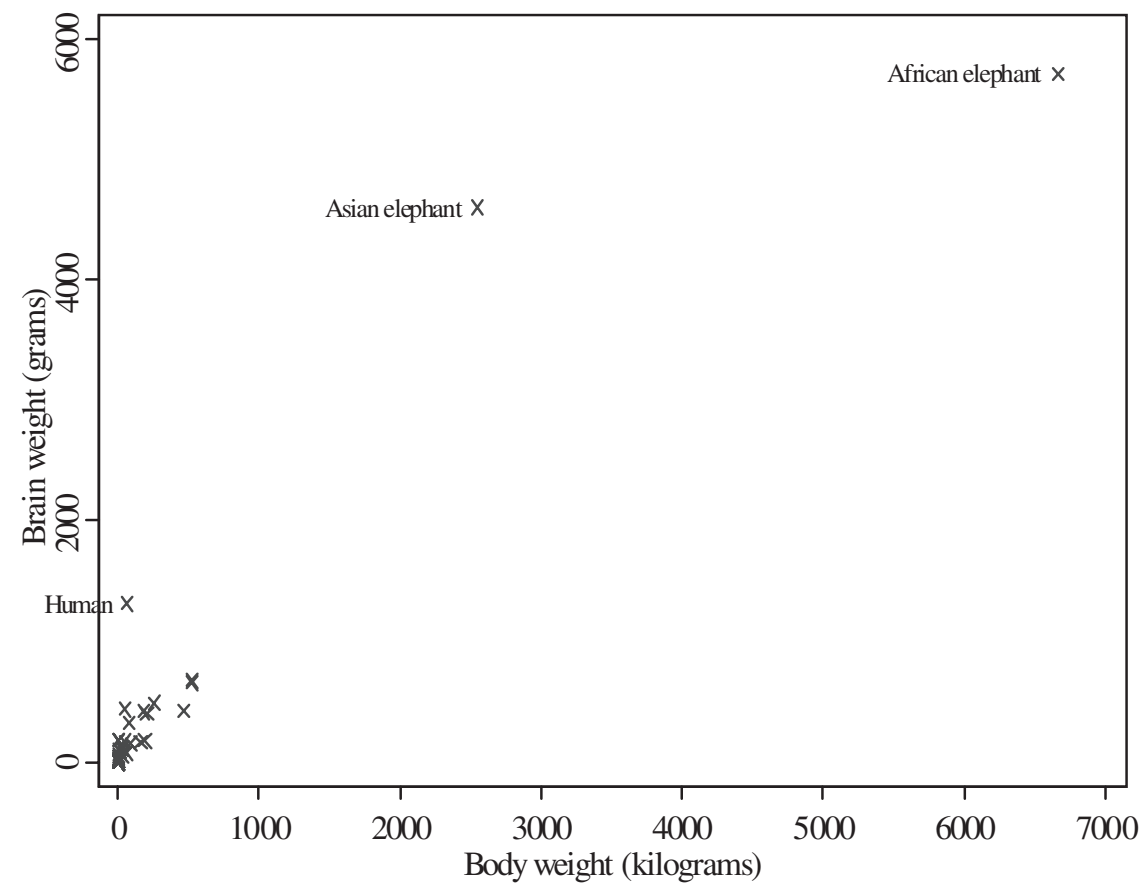

Source: Allison and Cicchetti, Science 1976.

corner with only a few stragglers elsewhere. Because of the wide variation of both variables, $\log$ transformations are obvious candidates. ${ }^{12}$

In this case, the obvious transformation candidate leads to highly satisfactory results. Figure 3 shows the same data as Figure 2, but with each variable transformed to logs. The existence of a strong, linear relation between brain weight and body weight is clear. The analyst who relied on Figure 2 to

\footnotetext{
${ }^{12}$ Sanford Weisberg, Applied Linear Regression 130 (1980). In a later edition, Weisberg states:

Apart from the three separated points for two species of elephants and for humans, the uneven distribution of points hides any useful visual information about the mean of BrainWt, given BodyWt. In any case, there is little or no evidence for a straight-line mean function here. Both variables range over several orders of magnitude from tiny species with body weights of just a few grams to huge animals of over $6600 \mathrm{~kg}$. Transformations can help in this problem.
}

Weisberg, supra note 11, at 148 . 
Figure 3: Transformed brain weight versus body weight, mammals.

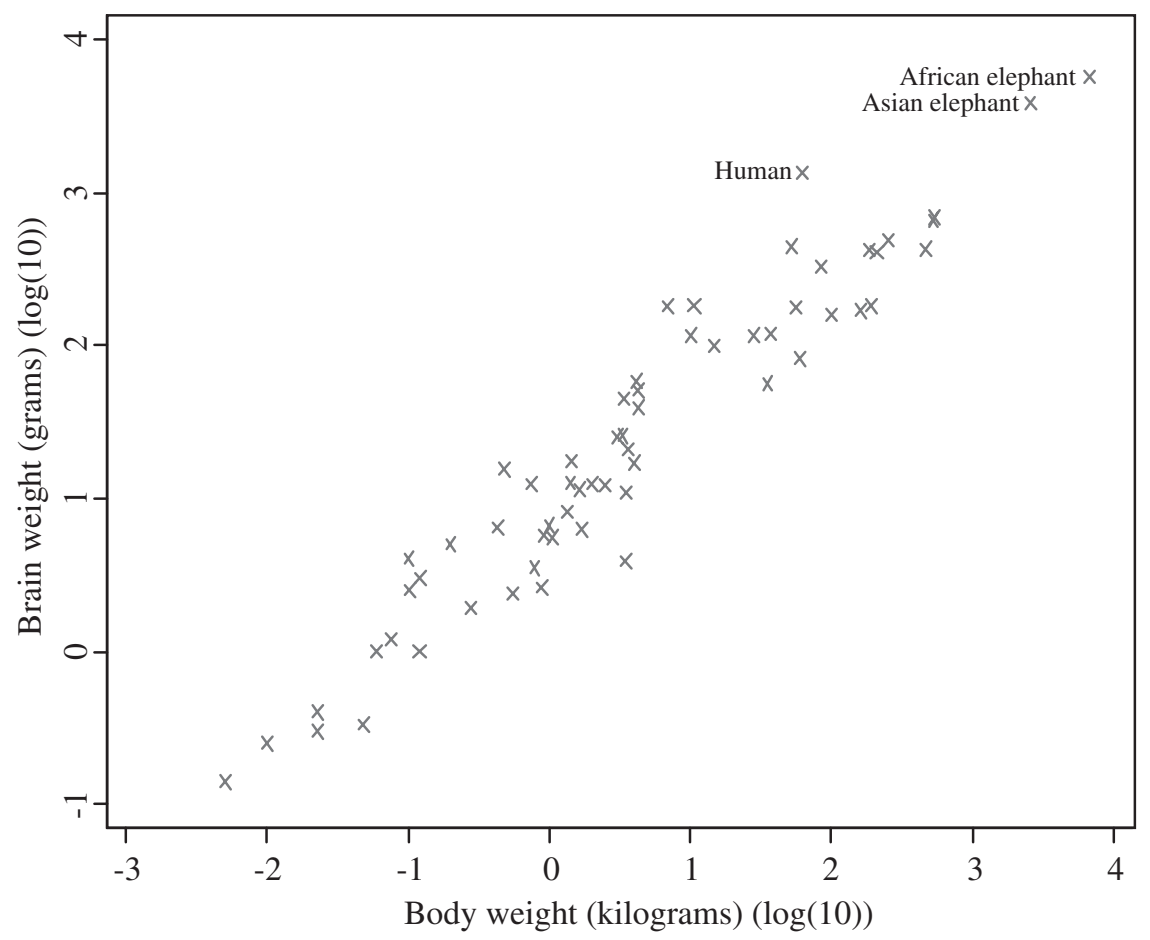

conclude that no significant relation exists between brain weight and body weight would be in error.

Much the same can be said about the punitive and compensatory damages data in Figure 1. Figure 1 is not helpful in exploring the relation between punitive and compensatory awards. As in the case of the brain-body weight data, most of the data points in the plot "are jammed into the lower left-hand corner." The graph "indicates immediately that some sort of transformation is required." Given the skewness suggested by Table 1, a standard statistical technique is to transform the data into logarithms. ${ }^{13} \mathrm{H}-\mathrm{V}$ err in

\footnotetext{
${ }^{13}$ Weisberg, supra note 11, at 148-50; Hamilton, supra note 11, at 19-20. In fact, simple log transformations may be inadequate for these data because of the method used to select them. The data were selected for their extremity—punitive awards had to exceed $\$ 100$ million to enter the sample. Statistical methods appropriate for extreme values, see Theodore Eisenberg \& Martin T. Wells, Analyzing Large Punitive Damages Awards (unpublished paper), and for the
} 
inferring the absence of a relation between punitive and compensatory awards based in part on an inappropriate model. ${ }^{14}$ The assumptions of ordinary least squares regression (OLS) are not satisfied..$^{15}$ One should expect, as $\mathrm{H}-\mathrm{V}$ report, that a regression model of Figure 1's data would not yield satisfactory results. But the model's poor results are not evidence of no relation or a weak relation between punitive and compensatory awards. Rather, the results suggest that an inappropriate model yields questionable results.

To better visualize the data, we transform them to base-10 logarithms and examine a second scatterplot.

Figure 4 is more revealing than Figure 1. One can now differentiate among the cases and the data reveal an upward-sloping relation, but with several awards disconnected from the mass of awards. Figure 4 also labels tobacco cases (as determined by case names with tobacco company defendants; Engle is also a tobacco case) as well as the large Exxon Valdez case. At least five tobacco cases are in the data-four are jury trials, one is a bench trial-and they are distinguishable from the mass of large punitive cases. The enormous stakes of the national tobacco settlement, as well as historical tobacco industry behavior, suggest why tobacco cases might follow a distinctive pattern. ${ }^{16}$ So, both knowledge of the social forces shaping tobacco awards and exploratory data analysis counsel in favor of attempting to account for any distinctive features of the tobacco cases.

\section{B. Regression Models of the Data}

Figure 5 shows the same data as Figure 4 but includes two linear regression lines that best fit subsets of the data. The higher regression line is limited to

censoring implicit in the selection mechanism should probably be employed. See Section II.C.3, infra. An additional approach would be to model the two groupings of data, as suggested by Figure 5, using mixture-regression techniques. See D.M. Titterington, Statistical Analysis of Finite Mixture Distributions (1986). For purposes of this presentation, we follow $\mathrm{H}-\mathrm{V}$ and explore OLS methods as applied to these data. The mixture-regression results are not substantively different from the OLS approach in Models 2 to 5 in Table 2.

\footnotetext{
${ }^{14}$ Hersch \& Viscusi, supra note 7, at 10.

${ }^{15}$ For example, a plot of residuals versus fitted values based on a regression using the untransformed data shows an unacceptable pattern. E.g., Weisberg, supra note 11, at 36-37; Weisberg (1980), supra note 12 , at 120 . See also note 26 , infra.
}

${ }^{16}$ See Theodore Eisenberg, Damage Awards in Perspective: Behind the Headline-Grabbing Awards in Exxon Valdez and Engle, 36 Wake Forest L. Rev. 1129 (2001). 
Figure 4: Punitive versus compensatory damages: punitive awards of at least $\$ 100,000,000,1985-2003$.

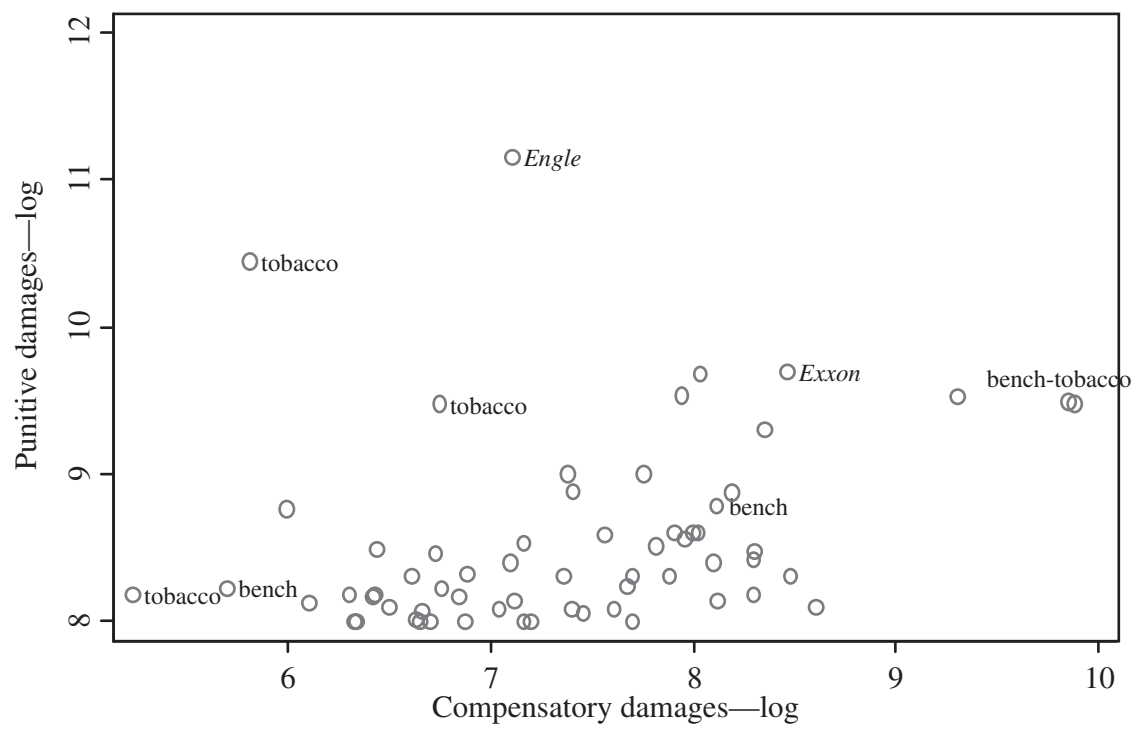

SOURCE: Hersch-Viscusi, Journal of Legal Studies 2004.

the five tobacco cases. The lower regression line includes the 58 other data points. The lines are nearly parallel, suggesting that tobacco cases can reasonably be accounted for by a dummy variable that shifts the regression model intercept upward. ${ }^{17}$

Assuming that OLS is a reasonable approach, ${ }^{18}$ we, following $\mathrm{H}-\mathrm{V}$, limit the sample to jury trials because the primary $\mathrm{H}-\mathrm{V}$ claim is that jury trials

\footnotetext{
${ }^{17}$ When the sample is limited to jury trials, as we do for the rest of this article, a model that uses an interaction term consisting of the product of a tobacco dummy variable times punitive damages $(\log )$ yields results similar to those using a tobacco dummy variable instead of the interaction term. In fact, the interaction term model is slightly superior to the dummy variable model, with an adjusted $r^{2}$ of 0.52 compared to 0.49 in Model 2 in Table 2 and a slightly lower Akaike information criteria. The key results for our purposes are (1) that accounting for tobacco cases, whether through an interaction term or a dummy variable, yields models substantially more persuasive than models that fail to account for tobacco cases, and (2) that reasonably accounting for tobacco cases shows a strong statistically significant association between punitive and compensatory damages.
}

\footnotetext{
${ }^{18}$ See note 13 , supra.
} 
Figure 5: Punitive versus compensatory damages: punitive awards of at least $\$ 100,000,000,1985-2003$.

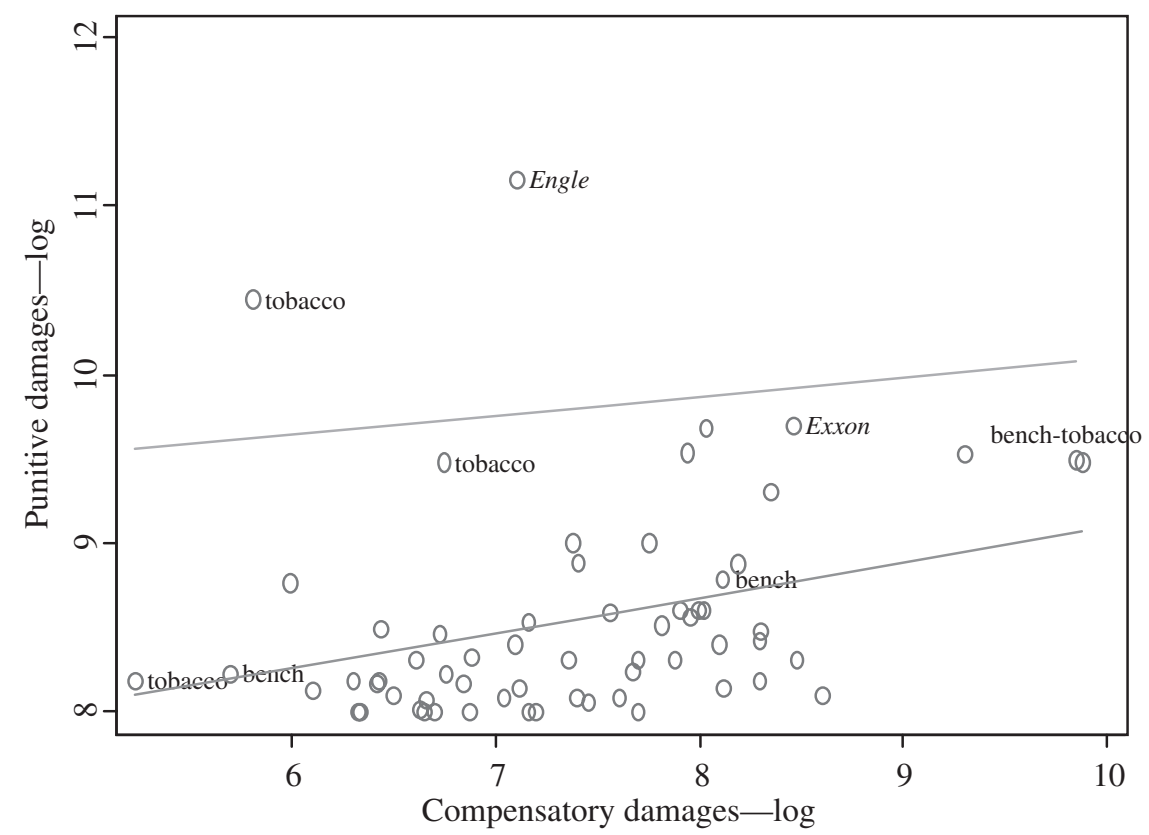

Source: Hersch-Viscusi, Journal of Legal Studies 2004.

exhibit no significant relation between punitive and compensatory damages. The dependent variable in Table 2's Models 1 and 2 is the log of punitive damages, ${ }^{19}$ and all models include a variable for "year" to pick up a possible linear time trend. Other explanatory variables are compensatory damages in Model 1 and compensatory damages and a tobacco dummy variable in Models 2 to 5 . Model 1 is most like the H-V log-based model,,${ }^{20}$ though we are unable to precisely replicate their results. We accept, for purposes of discus-

\footnotetext{
${ }^{19}$ Using the $\log$ of punitive damages as a dependent variable in a normal-distribution-based regression model is equivalent to assuming that the punitive damages follow a log normal distribution. See Norman L. Johnson, Samuel Kotz \& N. Balakrishan, Continuous Univariate Distributions (2d ed. 1994).
}

${ }^{20} \mathrm{H}-\mathrm{V}$ do not report having used models that try to control for time. 
sion, that Model 1, or the H-V log-based model, ${ }^{21}$ supports their claim of no significant association between punitive and compensatory awards.

Nevertheless, Table 2 suggests that $\mathrm{H}-\mathrm{V}$ erroneously concluded that no substantial, statistically significant association exists between punitive and compensatory damages. Model 2, which adds a single dummy variable for tobacco cases, yields an adjusted $r^{2}$ of nearly 0.5 and shows a highly significant association between punitive and compensatory damages. The $r^{2}$ is similar to the explanatory power of models of less extreme punitive damage awards. $^{22}$

\section{Assessing Regression Models}

Methodologically, however, it is premature to conclude the analysis. Just as sound regression technique requires graphically examining the data, sound technique also requires postestimation assessment of a model beyond the reported significance levels and the amount of variance explained.

1. Examining Residual Plots and the Need for Additional Transformations

Plots of residuals versus other quantities are a standard tool for finding failures of OLS assumptions. ${ }^{23}$ "The most common plot, especially useful in simple regression, is the plot of residuals versus fitted values." ${ }^{24}$ Examining a studentized residuals versus fitted plot of Model 2, shown in Figure 6, suggests that the pattern of residuals is not satisfactory. If the assumptions of OLS are satisfied, the plot ideally should show a random pattern, ${ }^{25}$ but Figure 5 suggests a pattern of residuals increasing with fitted values, an indication of nonconstant residual variance (heteroskedasticity). ${ }^{26} \mathrm{~A}$ test for heteroskedasticity suggests that one can reject the hypothesis of constant variance $(p<0.0001)$.

\footnotetext{
${ }^{21}$ Hersch \& Viscusi, supra note 7, at 10.

${ }^{22}$ Eisenberg et al., Predictability, supra note 1 .

${ }^{23}$ Weisberg, supra note 11 , at 36 .

${ }^{24} \mathrm{Id}$.

${ }^{25}$ Id. at $36-37$.

${ }^{26} \mathrm{~A}$ residuals versus fitted plot of Model 1 suggests both nonconstant variance and extreme outliers.
} 


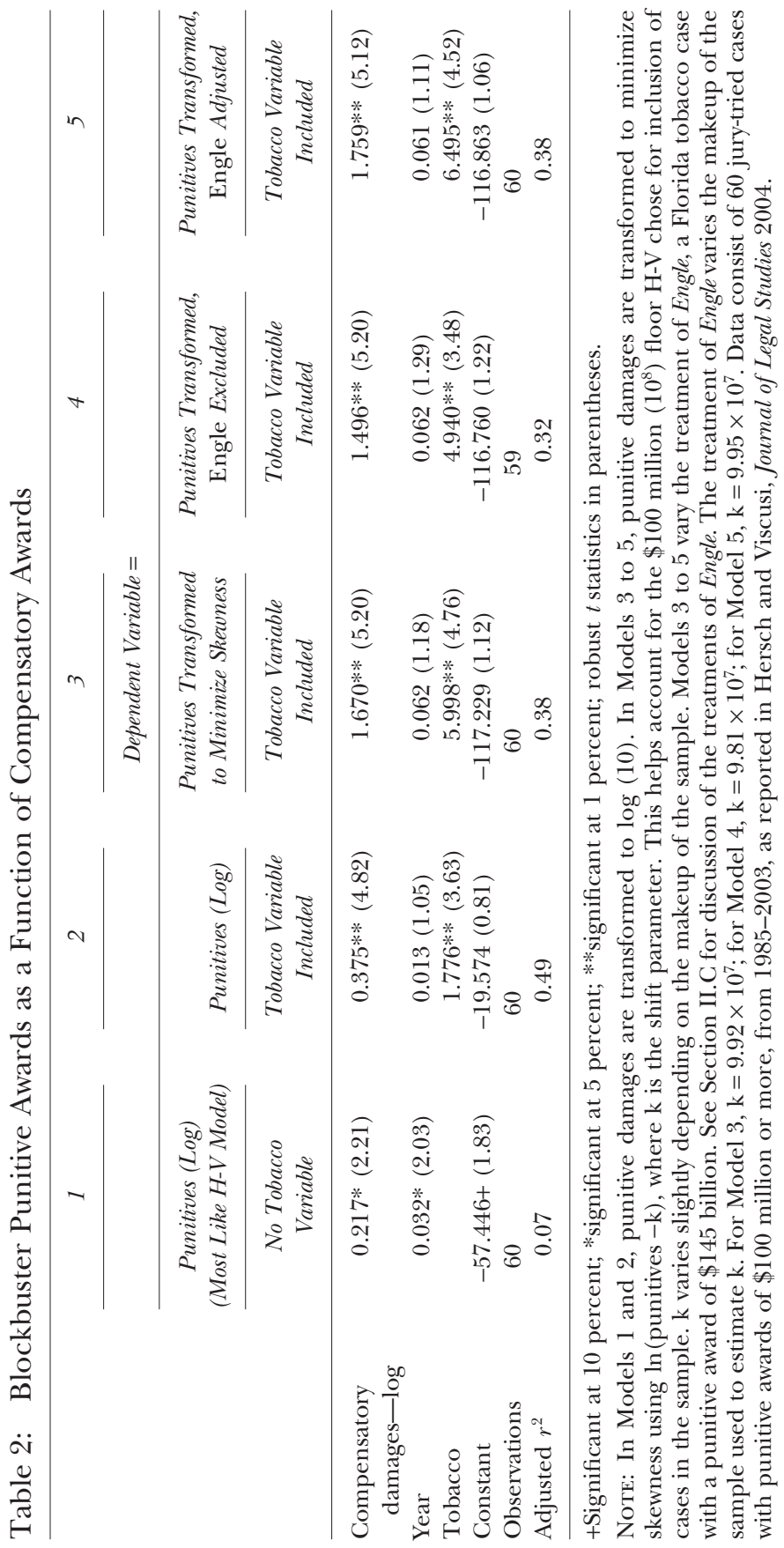


Figure 6: Studentized residuals versus fitted plot, dependent variable $=\log$ punitives.

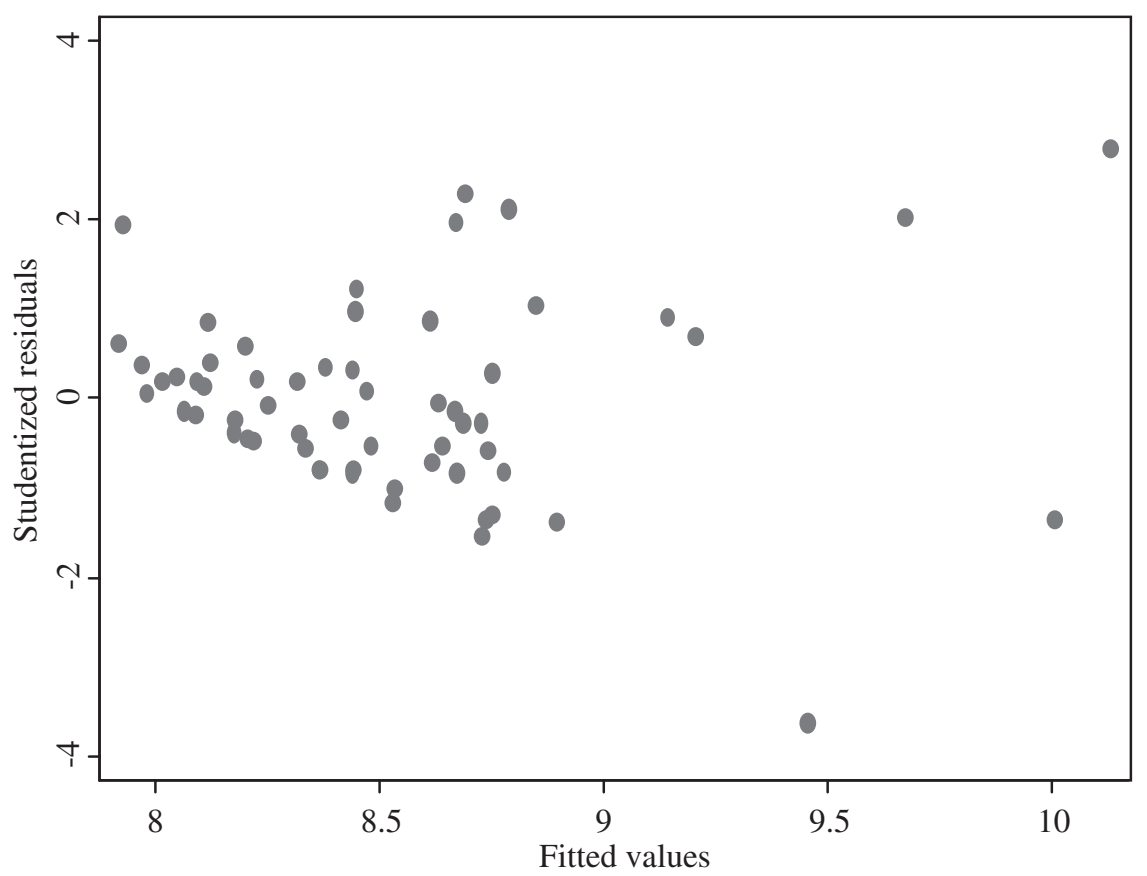

Note: Plot is of Model 2 in Table 2.

To help address the limitations of the models discussed so far, we employ a skewness-minimizing transformation of the dependent variable, a more refined transformation than the simple log transformation. It is based on a one-parameter shifted log transformation, where the shift minimizes the skewness of the dependent variable. In this case, the optimal shift parameter was identified using the "Inskew0" function in Stata version 9.1. The resulting shift parameter, $9.92 \times 10^{7}$ for Model 3, is a small amount less than the punitive damages floor selected by $\mathrm{H}-\mathrm{V}$, which equals $10^{8}$. The transformed dependent variable is thus $\log$ (punitives $-9.92 \times 10^{7}$ ). It shifts the dependent variable's distribution to accommodate the arbitrary floor of $\$ 100$ million $\left(10^{8}\right)$ in punitive damages used as the data selection criteria. Since this transformation has this interpretable link to the data, we use it instead of another familiar one-parameter transformation, for example, the Box-Cox transformation. Since the shift parameter, $9.92 \times 10^{7}$, is slightly 
smaller than the censoring level imposed on the data, the transformed variable leaves a small left-tail for the floor values of punitive damages in the data. ${ }^{27}$

Model 3 in Table 2 employs the skewness-minimized dependent variable. It shows an even more statistically significant relation between the two key explanatory variables, tobacco and compensatory damages $(\log )$, and the dependent variable. However, Model 3 also explains less of the variance than Model 2, with an adjusted $r^{2}$ of 0.38 compared to 0.49 in Model 2. So the significant relation between punitive and compensatory damages persists but the model does not explain as much of the variance.

Postestimation analysis confirms that Model 3 has desirable properties compared to Model 2. Figure 7 is a studentized residuals versus fitted plot for Model 3. The scatterplot shows a more random pattern than Figure 6. The plot suggests that Model 3 better satisfies OLS assumptions than Models 1 or 2. A test for the presence of heteroskedasticity indicates that one cannot reject the hypothesis of constant variance $(p=0.266)$. Other OLS assumptions are reasonably well satisfied ${ }^{28}$ but we are primarily interested in the relative merits of the reported models, not the absolute propriety of the models. The unbalanced nature of the sample-the relatively few tobacco cases-suggests using bootstrap methods ${ }^{29}$ to assess the robustness of the model. Such methods yield essentially the same results as those reported here. Both visually and statistically, Model 3 should be preferred over Models 1 and 2 if one is attendant to the OLS assumptions.

It is also instructive to compare how the most reasonable H-V-like model (because it transforms the data to logs), Model 1 in Table 2, compares

\footnotetext{
${ }^{27}$ Furthermore, the transfer parameter is selected so that the lower-end increments and upperend increments are symmetric about the mean transformed value and have a range of six standard deviations.

${ }^{28}$ The standard OLS assumptions of the appropriateness of a linear relation (see Figure 8, top figure) and constant variance are addressed in the text. In addition, there is no correlation between the explanatory variables and the residuals, and multicollinearity, see Weisberg, supra note 11, at 214-16, as measured by variance inflation factors, is not a problem. Assumptions about the normality of the residuals appear reasonably satisfied in Model 3. A Shapiro-Wilk test for normality yields $p=0.121$. The assumption of the absence of serial correlation, for example, Weisberg, supra note 11, at 226 (noting that, in time series, use of lagged dependent variables can help account for serial correlations between consecutive measurements), is not seriously at issue here.
}

${ }^{29}$ Bradley Efron \& Robert J. Tibshirani, An Introduction to the Bootstrap (1993). 
Figure 7: Studentized residuals versus fitted plot, dependent variable $=\log$ punitives, skewness minimized.

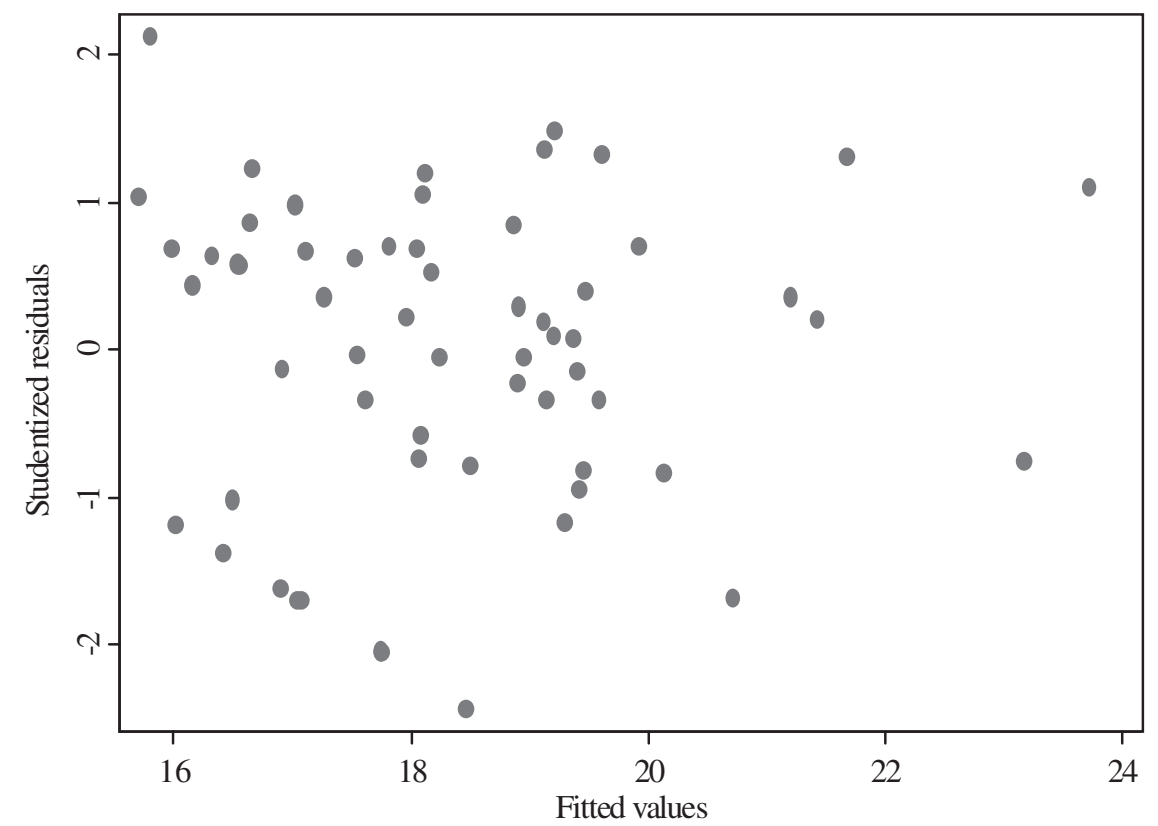

Note: Plot is of Model 3 in Table 2.

in fitting the data with Table 2's Model 3. Figure 8 shows, as small circles, the fitted values of the regression models.

Figure 8's bottom figure shows graphically how poorly the H-V model fits the tobacco cases. The predicted values nowhere come close to the observed values. Model 3, on the other hand, shown in the top figure, captures reasonably well the central tendencies in both the tobacco cases' awards and in the mass of awards. It is not surprising that Model 1 has such low explanatory power. It is poorly specified to fit these data.

\section{Alternative Treatments of Engle}

Further refinement is possible. Figure 4 shows at least one possible outlier case, the case with the highest punitive award, a punitive award of more than 11 in the log-10 scale, corresponding to a punitive award of more than $\$ 100$ billion. It is not just that this case involves a high punitive award; as striking is that the $\$ 100$ billion punitive award is in a case with a compensatory award 
Figure 8: Comparison of fit of models: Eisenberg-Wells (top) and HeischViscusi (bottom).
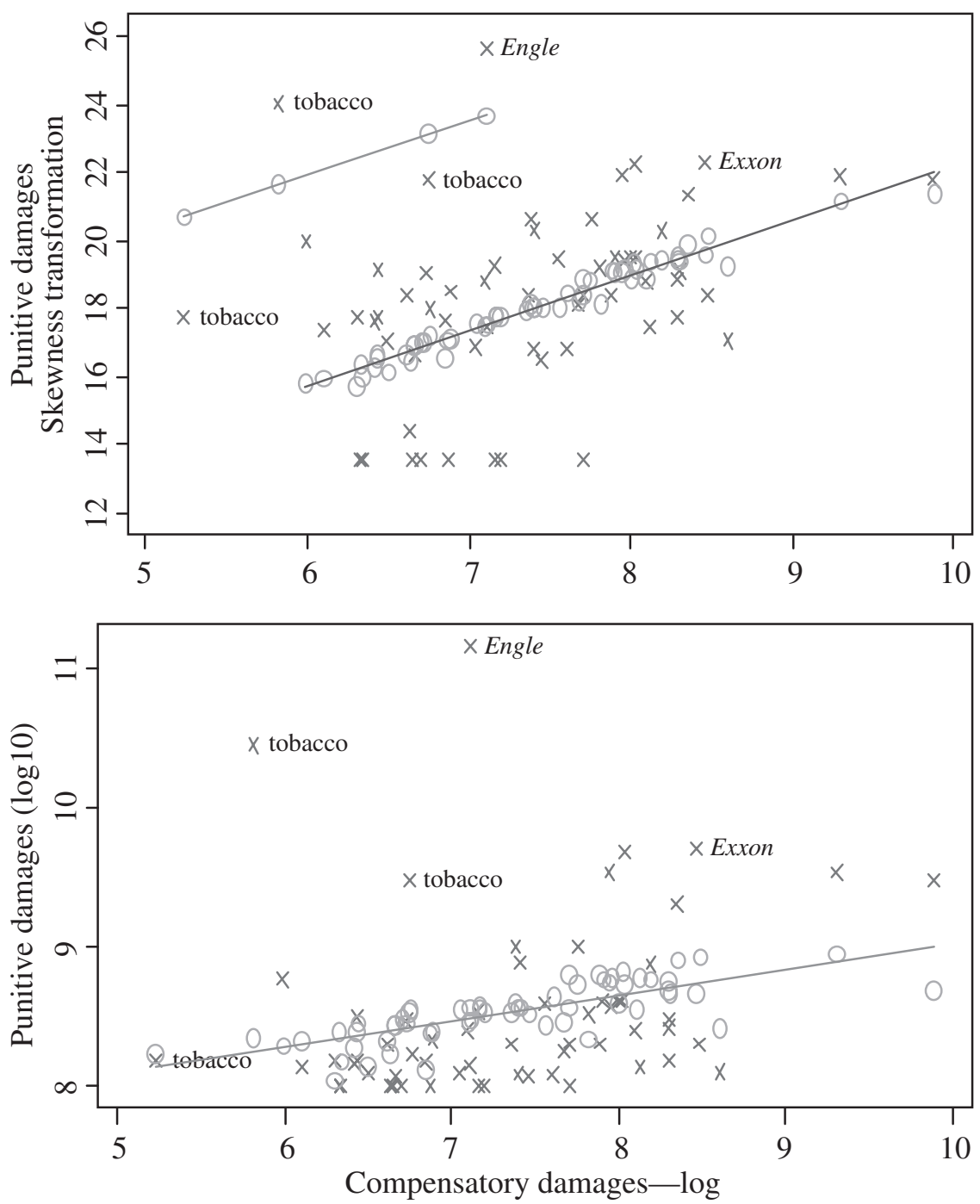

Note: Top figure is based on Model 3 in Table 2, which includes a dummy variable for tobacco and employs a skewness-minimizing transformation that helps account for the arbitrarily selected floor of $\$ 100$ million in the dependent variable in the $\mathrm{H}-\mathrm{V}$ data. The bottom figure is based on Model 1 in Table 2, which is the H-V log transform model, with an additional variable for year (though the year variable has no material effect on the results). Circles in both figures indicate fitted values based on Table 2's regression models, xs indicate observed values. Lines are best-fitting lines for the tobacco cases (tobacco dummy variable $=1$ ) and nontobacco cases (tobacco variable $=0$ ) in the top figure and for all cases combined in the bottom figure. The bottom figure shows that the $\mathrm{H}-\mathrm{V}$ model poorly fits the tobacco cases and other large awards. 
of much less than $\$ 100$ million. The punitive-compensatory ratio is staggeringly high, over 1,000 to 1 .

Statistical techniques exist that deal with outliers in data, but the soundest initial advice with respect to outliers is to check one's data. ${ }^{30}$ Returning to the H-V data reveals that the suspect case is the famous Florida tobacco case, Engle v. R.J. Reynolds Tobacco Co., ${ }^{31}$ in which a jury awarded plaintiffs $\$ 145$ billion against the tobacco industry. The award was on behalf of a plaintiff class and the $\$ 145$ billion figure in the $\mathrm{H}-\mathrm{V}$ data is correct.

But the Engle award was struck on appeal and deeper analysis of the case's numbers suggest that including the trial-level award in the analysis, or including it without modification, is questionable. The compensatory award figure $\mathrm{H}-\mathrm{V}$ use for Engle in the model in which they include that case is not defensible. The Florida class of plaintiffs is estimated at up to 500,000 persons. ${ }^{32}$ The jury had already awarded about $\$ 12$ million in compensatory damages to four representative plaintiffs. ${ }^{33}$ If all 500,000 persons in the punitive class suffered $\$ 1$ million in harm, the compensatory award, based solely on harm, would be $\$ 500$ billion. A punitive award of $\$ 145$ billion is of the same order of magnitude and less than $\$ 1$ of punitive damages per dollar of compensatory award. So if class action certification was correct, a question not for the jury, and the compensatory awards were representative of the class harm, the $\$ 145$ billion punitive award should be not be associated with the $\$ 12$ million used by $\mathrm{H}-\mathrm{V}$ to measure the compensatory award. Rather, it

\footnotetext{
${ }^{30}$ For example, A.A. Afifi \& Virginia Clark, Computer-Aided Multivariate Analysis 43 (1984) (recommending that outliers be checked against the original data for error).

${ }^{31}$ Engle et al. v. R.J. Reynolds Tobacco Co. et al., No. 94-8273 CA 22 (Fla. Cir. Ct., 11th Jud. Dist., Dade Cty. Nov. 6, 2000) (approving $\$ 145$ billion dollar award), rev'd, 853 So. $2 d 434$ (Fla. App. 2003), review granted, 873 So. 2d 1222 (Fla. 2004). For discussion of the tobacco verdict, see Marc Kaufman, Tobacco Suit Award: \$145 Billion; Fla. Jury Hands Industry Major Setback, Wash. Post, July 15, 2000, at A01.

${ }^{32}$ Tobacco Companies Ordered to Pay $\$ 145$ Billion in Punitive Damages, 15 Andrews Tobacco Ind. Litig. Rep. 3 (2000). For reports that the class might be 700,000 persons, see Marianne Lavelle \& Angie Cannon, Chewing Big Tobacco: Will the $\$ 145$ Billion Verdict Stand?, U.S. News \& World Rep. July 24 (2000); Richard Hubbard, Closing Arguments Near Completion in Fla. Tobacco Trial, Dow Jones News Serv. July 12 (2000); Myron Levin, Jury Asked to Hit Cigarette Firms for \$154 Billion Tobacco: Lawyer in Florida Class Action Says Record-Shattering Verdict Would Be "Just" Punishment for Harm, L.A. Times July 11 (2000), 2000 WL 2259395.

${ }^{33}$ Tobacco Companies Ordered to Pay $\$ 145$ Billion in Punitive Damages, 15 Andrews Tobacco Ind. Litig. Rep. 3 (2000). However, one of those awards was questionable in light of a statute of limitations problem. Id.
} 
should be associated with an unknowable number, but the correct number likely exceeds $\$ 500$ billion. Including Engle without modification associates the compensatory harm for four persons with punitive damages awarded to hundreds of thousands of putative victims. H-V do report a model that deletes Engle, ${ }^{34}$ a reasonable decision. However, including Engle in another model without modification, and claiming that the model is a poor one, is not justifiable.

Model 4 in Table 2 omits Engle, and Model 5 includes it with an adjustment as described above. Models 3, 4, and 5 present a reasonably consistent statistical story. We conclude that, subject to the limits of using OLS on these data, a strong, statistically significant association exists between punitive and compensatory awards, even in the extreme set of awards assembled by H-V. Additional models, not reported here, establish that the association does not depend on the tobacco cases. Even excluding those cases, a highly statistically significant association exists between punitive and compensatory awards in jury cases in the H-V sample $(p<0.001)$.

3. Additional Measures to Deal with Limiting the Sample to Cases with $\$ 100$ Million Awards

As noted above, the $\mathrm{H}-\mathrm{V}$ data have the distinctive feature of being limited to cases with punitive awards of $\$ 100$ million or more. Although the log transformation with shift parameter reported as Model 3 in Table 2 gives reasonably satisfactory OLS results, it is helpful to explore the distribution of the transformed variable. Figure 9 shows the distribution of punitive awards, as transformed. Figure 9 shows a reasonably normal-looking distribution for much of its range, but with a distinctive peak in the left tail of the distribution. This peak results from the fact the H-V data contain eight observations at their low-end censoring point, $\$ 100$ million. Although the shift-parameterbased log transformation helps account for the location of the distribution, it does not expressly account for the distribution's distinctive shape.

We explore two approaches to expressly address the shape of the distribution. First, the $\$ 100$ million censoring point is obviously arbitrary. Suppose the H-V data were limited to cases that exceed $\$ 100$ million in punitive damages rather than to cases that equaled or exceeded $\$ 100$

\footnotetext{
${ }^{34}$ The model in which H-V exclude Engle also seemingly fails to account for the distinctive pattern of tobacco awards. Hersch \& Viscusi, supra note 7, at 10.
} 
Figure 9: Distribution of transformed punitive damages.

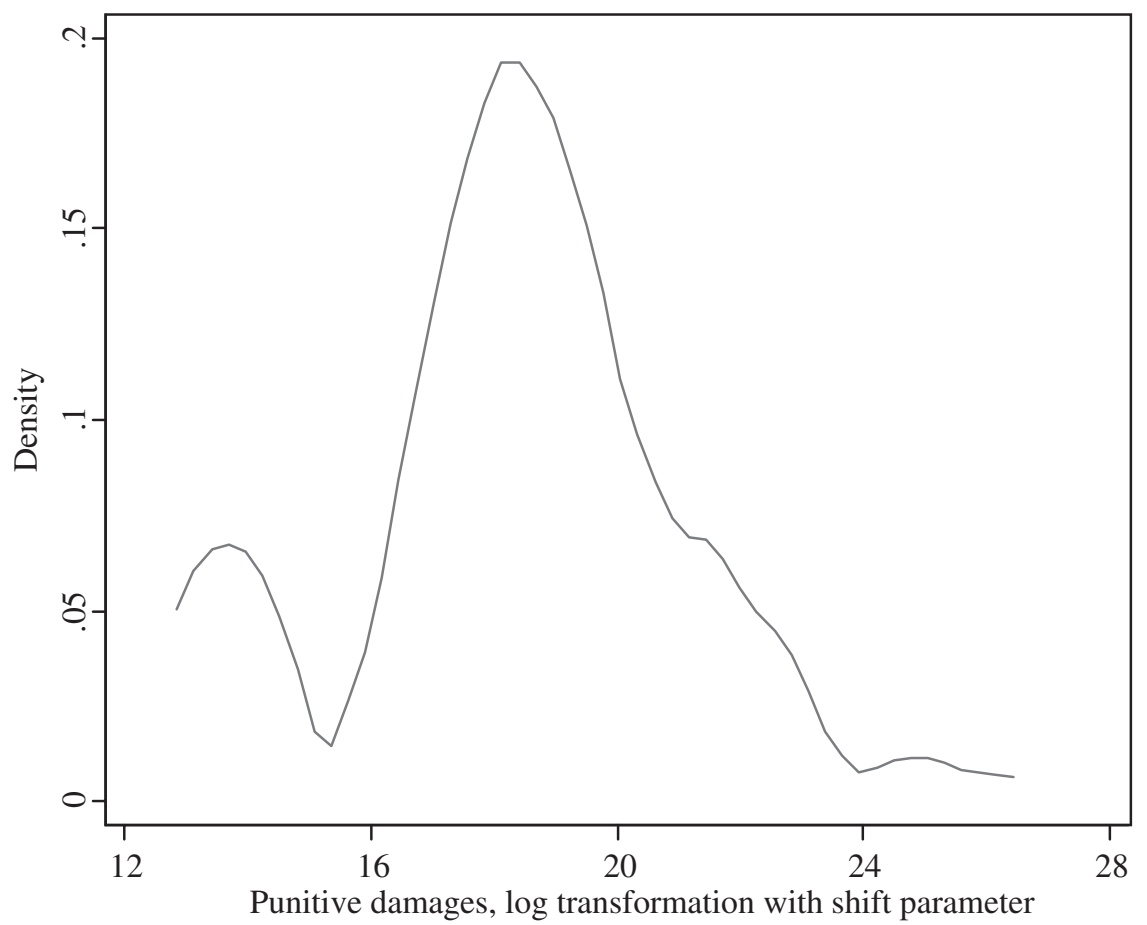

Note: The figure is a kernel density estimate of the distribution of the transformed dependent variable used in Model 3 of Table 2. Punitive damages are transformed to minimize skewness using $\ln$ (punitives $-\mathrm{k}$ ), where $\mathrm{k}$ is the shift parameter, $\mathrm{k}=9.92 \times 10^{7}$. Data consist of 60 jury-tried cases with punitive awards of $\$ 100$ million or more, from 1985-2003, as reported in Hersch and Viscusi, Journal of Legal Studies 2004.

million. Would that materially change the models? Second, the censoring at the low end of the sample suggests exploring tobit models with censoring at $\$ 100$ million.

Table 3 reports results for these models. Table 3's first model omits the eight cases with punitive awards of $\$ 100$ million, and uses a shifted log transformation that reflects the modified distribution of the dependent variable. Table 3's second model accounts for the data selection by using a tobit model. Both models are analogous to Model 3 in Table 2. The model that omits the eight cases again shows a strong, significant association between punitive and compensatory damages and again indicates the importance of accounting for the tobacco cases. The tobit model suggests an even 
Table 3: Regression Models Addressing Limiting the Sample to Cases with Punitive Awards of $\$ 100$ Million or More

\begin{tabular}{|c|c|c|}
\hline & 1 & 2 \\
\hline & $\begin{array}{c}\text { Drop Cases with Punitives } \\
\text { Equal to } \$ 100 \text { Million }\end{array}$ & $\begin{array}{c}\text { Tobit Model } \\
\text { with Left-Censoring }\end{array}$ \\
\hline Compensatory damages-log & $1.325^{* *}(4.05)$ & $1.798 * *(4.76)$ \\
\hline Tobacco & $4.914 * *(3.82)$ & $6.307 * *(4.81)$ \\
\hline Year & $0.091(1.67)$ & $0.061(0.81)$ \\
\hline Constant & $-173.037(1.57)$ & $-116.329(0.77)$ \\
\hline Observations & 52 & 60 \\
\hline Adjusted $r^{2}(1)$; pseudo $r^{2}(2)$ & 0.38 & 0.10 \\
\hline
\end{tabular}

Robust $t$ statistics in parentheses; +significant at 10 percent; *significant at 5 percent; **significant at 1 percent.

Note: Punitive damages, the dependent variable, is transformed to minimize skewness using $\ln$ (punitives $-\mathrm{k}$ ), where $\mathrm{k}$ is the shift parameter. $\mathrm{k}$ varies slightly depending on the makeup of the sample. For Model 1, $\mathrm{k}=1.01 \times 10^{8}$; for Model 2, $\mathrm{k}$ is the same as in Model 3 of Table 2, $9.92 \times 10^{7}$. Data for Model 1 consist of 52 jury-tried cases with punitive damages greater than $\$ 100$ million. Data for Model 2 consist of 60 jury-tried cases with punitive awards of $\$ 100$ million or more. Model 2 is a tobit model with eight left-censored observations. Data for both models cover the years 1985-2003, as reported in Hersch and Viscusi, Journal of Legal Studies 2004.

stronger association between compensatory damages and punitive damages (coefficient $=1.798$ compared to 1.670 in Table 2, Model 3) and between tobacco and punitive damages (coefficient $=6.307$ compared to 5.998 in Table 2, Model 3).

\section{Conclusion}

A more statistically sound OLS approach undermines the claim that for "the blockbuster award sample, the value of the compensatory award is not a significant predictor of the value of punitive damages." ${ }^{\prime 5}$ Blockbuster punitive awards, like other punitive awards, show a strong association with compensatory awards. The statistical lessons are that one should graph one's data and check that the assumptions of OLS regression are satisfied before endorsing a model. We emphasize that we are not certain that traditional OLS techniques are necessarily the ones to employ for these extreme data and that models of the full range of cases might require introducing some

${ }^{35} \mathrm{Id}$. 
curvature into the punitive-compensatory relation. ${ }^{36}$ But $\mathrm{H}-\mathrm{V}$, like many researchers, understandably resort to OLS as a kind of default statistical methodology. That methodology should be employed more rigorously than is done in the H-V article.

${ }^{36}$ Theodore Eisenberg \& Martin T. Wells, Punitive Awards After BMW, a New Capping System, and the Reported Opinion Bias, 1998 Wis. L. Rev. 387, 391-92. 